\title{
América Latina y el tercermundismo en los medios de comunicación
}

\section{Latin America and Third-Worldism in the Media}

\section{América Latina e o Terceiro mundismo nos meios de comunicação}

\author{
Abner Barrera-Rivera \\ Académico \\ Instituto de Estudios Latinoamericanos \\ Universidad Nacional, Costa Rica \\ DOI: https://doi.org/10.15359/tdna.35-66.4 \\ Recibido: 25/06/2019 \\ Aceptado: 10/09/2019
}

\section{Resumen}

Este artículo analiza cuatro entrevistas llevadas a cabo por periodistas de diferentes medios de comunicación de Estados Unidos, Gran Bretaña, Perú y Costa Rica a Rafael Correa, cuando era presidente de Ecuador. Las entrevistas abordan temas de derechos humanos, democracia, reelección presidencial, América Latina, Cuba, los Estados Unidos, la libertad de prensa y la Organización de Estados Americanos. En cada una de ellas

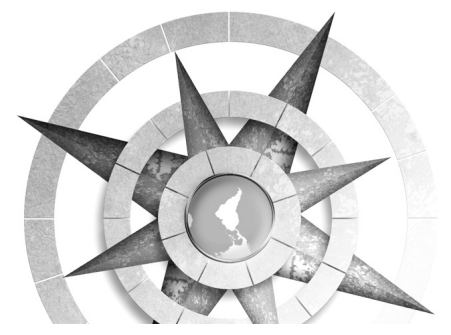

Rafael Correa cuestiona las perspectivas que los entrevistadores tienen acerca de América Latina. A partir del intercambio de opiniones con ellos, hace su propio análisis y muestra que los medios de comunicación ahí representados expresan visiones y valoraciones que él cataloga de tercermundistas, etnocentristas y neocolonialistas sobre los Gobiernos progresistas de América Latina. Se concluye que las ideas desarrolladas por Correa respecto a las visiones de los periodistas contienen razonamientos históricos, políticos, sociales y culturales persuasivos, que dejan a los entrevistadores sin argumentos propios.

Palabras clave: América Latina, medios de comunicación, tercermundismo, neocolonialista, etnocentrismo, sumisión 


\begin{abstract}
This article is an analysis of interviews carried out by journalists from different media from The United States, Great Britain, Peru and Costa Rica, to Rafael Correa while he was still president of Ecuador. The interviews address the topics of Human rights, democracy, and presidential reelection, Latina America, Cuba, the United States, Press Freedom and the OEA. In each of these interviews, former president Rafael Correa questions the perspectives and approaches of the interviewers on America Latina. From this exchange of opinions with his Interviewers, Correa makes his own analysis and shows that the mass media there represented, express their visions and perspectives on the progressive governments of America Latina which he considers to be ethnocentric, neo colonialist and third world visions. In conclusion, the ideas here developed by the interviewee in regards to the visions of the journalists, contain persuasive historical, political, social and cultural reasoning, which render the Journalists with no properreasoning.
\end{abstract}

Keywords: Latin America, mass media communication, Third World, neo-colonialism, ethnocentrism, submission.

\section{Resumo}

Este artigo analisa quatro entrevistas realizadas por jornalistas de diferentes meios de comunicação dos Estados
Unidos, Grã-Bretanha, Peru e Costa Rica com Rafael Correa, quando ele era presidente do Equador. As entrevistas cobrem temas como direitos humanos, democracia, reeleição presidencial, América Latina, Cuba, Estados Unidos, liberdade de imprensa e a Organização dos Estados Americanos. Em cada um deles Rafael Correa questiona as perspectivas que os entrevistadores têm sobre a América Latina. A partir da troca de opiniões com eles, ele faz sua própria análise e mostra que a mídia ali representada expressa visões e avaliações que ele cataloga como terceiro mundo, etnocêntrico e neocolonialista sobre os governos progressistas da América Latina. Conclui-se que as idéias desenvolvidas por Correa a respeito das opiniões dos jornalistas contêm raciocínios históricos, políticos, sociais e culturais persuasivos, o que deixa os entrevistadores sem argumentos próprios.

Palavras chave: América Latina, meios de comunicação, Terceiro-mundismo, neocolonialismo, etnocentrismo, submissão.

\section{Introducción}

La expresión tercermundismo ha sido utilizada con diferentes propósitos tanto en las ciencias sociales como en los medios de comunicación. El origen de su uso se encuentra primero en las ciencias sociales, que recurrieron a ella con el propósito de denominar a los países que durante la Guerra Fría no estuvieron directamente 
involucrados en ella. Después se trató de usar el concepto relacionándolo con las condiciones socioeconómicas de los países caracterizados por la pobreza y por la dependencia hacia las economías centrales. Pero han sido los medios de comunicación los que han usado el término con distintos propósitos, lejos de sus orígenes. En entrevistas realizadas al entonces presidente Rafael Correa se desarrollaron diálogos intensos, en los cuales él le da una reorientación al significado de tercermundismo, que es desconocido para los propios comunicadores.

Este artículo consiste en un análisis de la connotación que este término tiene para Rafael Correa. El análisis se hace a partir de cuatro entrevistas que le fueron realizadas en momentos distintos por medios de comunicación, entre el 2012 y el 2015. Se trata de entrevistas polémicas no solo por los temas que se abordaron (los liderazgos políticos en América Latina, los medios de comunicación, la reelección presidencial, la Organización de Estados Americanos, los Estados Unidos, Cuba, los derechos humanos, entre otros), sino también por la forma cómo se realizaron. El lector comprenderá el significado del concepto tercermundismo propuesto por Rafael Correa y cómo está presente en la visión que la gente tiene de América Latina.

\section{Algunas referencias en torno al término tercermundismo}

Fue el sociólogo y economista francés Alfred Sauvy (1898-1990) quien por primera vez en 1952 utilizó el término tercer mundo en un artículo titulado "Tres mundos, un planeta" (Brichall, 2011). Recurrió a esa designación para agrupar a los países en relación con lo que fue la Guerra Fría. Para él, el primer mundo lo integraban todos los países que eran aliados de los Estados Unidos, el segundo mundo lo componían los países vinculados a la ex Unión de Repúblicas Socialistas Soviéticas (URSS) y el tercer mundo estaba compuesto por todas las naciones que no se encontraban directamente involucradas en la Guerra Fría. El autor planteaba en su artículo que el destino del planeta estaba en manos de dos grandes bloques, los cuales se encontraban enfrentados durante el tiempo que duró la Guerra Fría (1945-1989); el bloque capitalista lo encabezaba Washington y el bloque comunista Moscú, pero en ninguno de ellos estaban presentes muchas naciones, a las cuales él denominó países del tercer mundo, y que se caracterizaban por ser países pobres, explotados y saqueados. En ese uso inicial del término tercer mundo no había una connotación peyorativa respecto a los países que formaban parte de ese grupo.

Después de la nominación dada por Sauvy, en los años sesenta y desde las

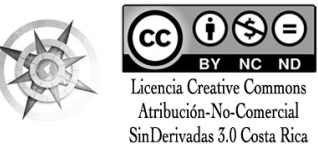


ciencias sociales se empezó a relacionar la expresión primer mundo con el conjunto de naciones económicamente desarrolladas e industrializadas; el segundo mundo con las naciones cuyas economías eran emergentes; y el tercer mundo con los países que se encontraban en una situación de desventaja, por su subordinación económica a los otros dos mundos, experimentando así un desarrollo débil en su economía. Con la desaparición del socialismo histórico esas designaciones y concepciones variaron. Al respecto, Houtart (2004) señala que la caída del socialismo real en el este europeo puso fin a la validez del concepto, una vez que el "segundo mundo" ya no existía como una oposición al "primero” y empezaba a entrar en una lógica económica y política similar.

Posteriormente, cuando se hizo referencia al tercer mundo se señalaba a los países que se caracterizaban por vender materias primas al primer mundo y que tenían poca o ninguna participación como actores principales en las grandes decisiones a nivel mundial (en todo caso su participación era subordinada). En los países del llamado tercer mundo sobresalían los escasos servicios de asistencia social, las desigualdades socioeconómicas, los elevados índices de pobreza, el empobrecimiento, el analfabetismo, las escasas condiciones de salud, entre otros. Esta situación fue aprovechada por los países centrales para incorporar a esa gran población como mano de obra barata; por eso muchas empresas del primer mundo se instalaron en los países del tercer mundo.

\section{El tercermundismo como ideología}

De ese primer uso del concepto tercer mundo se pasó en los años setenta al uso del término "tercermundista”, pero se lo empleó en un sentido diferente. Desde posiciones políticas conservadoras se entendía por tercermundismo a una doctrina política relacionada a los grupos de izquierda, que dividía a los países en dos sectores: las naciones desarrolladas y las naciones subdesarrolladas, sosteniendo que los logros alcanzados por los países desarrollados se debían a la explotación y al saqueo de los países subdesarrollados; es decir, la riqueza de los primeros explicaba la pobreza de los segundos, y viceversa. A partir de esta interpretación, ese pensamiento de izquierda asumió posiciones de denuncia contra el colonialismo, el neocolonialismo, el imperialismo, el capitalismo y el libre comercio.

Pero la expresión tercermundista se utilizó también con un sentido peyorativo, por ejemplo, en algunos casos, para señalar a los gobernantes y a los Gobiernos cuyos países eran pobres, más aún si esos presidentes no se conducían según las políticas económicas dictadas por los organismos financieros internacionales. Esta forma de usar el término ha sido 
constante por parte de los publicistas del neoliberalismo y puede constatarse en los editoriales y las páginas de opinión de los grandes medios de comunicación en las últimas tres décadas. Utilizaron ese concepto con el propósito de denostar específicamente a los gobiernos progresistas de la región. Desde esta visión, entonces políticos como Hugo Chávez, Néstor Kirchner, Rafael Correa, José Mujica, Evo Morales, Daniel Ortega, Cristina Fernández, Luiz Inácio Da Silva, Dilma Rousseff y Nicolás Maduro son dirigentes que tuvieron y tienen a su cargo posiciones y/o Gobiernos tercermundistas. Eso significa -según sus críticos-que se trata de políticos antimodernos, estatistas, atrasados, antiprogreso, anti-mercado, nacionalistas, primitivistas y subsidiadores.

Aunque se utiliza el término tercermundista para referirse a los Gobiernos cuyas naciones sufren condiciones de pobreza económica y social, sin embargo, no se dice lo mismo cuando, tratándose de esos mismos países pobres, quienes los gobiernan son presidentes neoliberales, en cuyas Administraciones las condiciones sociales y económicas de la gente empeoró (Sierra, 2012); crecieron las desigualdades sociales, el desempleo, la explotación, la exclusión, la pobreza; se privatizaron empresas claves de la economía; se redujo la inversión social; y se facilitaron los negocios del capital transnacional. Eso continuó sucediendo recientemente con Sebastián
Piñera (Chile), Vicente Fox (México), Álvaro Uribe (Colombia), Juan Manuel Santos (Colombia), Óscar Arias (Costa Rica), Laura Chinchilla (Costa Rica), Pedro Pablo Kuczynski (Perú), Mauricio Macri (Argentina), Michel Temer (Brasil), entre otros. Estos presidentes desarrollaron políticas económicas neoliberales diseñadas y promovidas por organismos financieros internacionales como el FMI, el BM y el BID, y no fueron catalogados como Gobiernos tercermundistas, sino como Gobiernos en vías de desarrollo, orientados al progreso y a la prosperidad.

Persiste todavía hoy aquella ideología que sostiene que el subdesarrollo es una etapa del camino al desarrollo, algo así como la infancia del desarrollo. Esta es una manera de negar los hechos históricos que explican que el subdesarrollo de las naciones es el resultado del desarrollo de los países más poderosos. Galeano ha sostenido que los pueblos de la Patria Grande han estado trabajando por más de cinco siglos para el desarrollo ajeno, contribuyendo con su pobreza a la riqueza de otros. Plantea algunas preguntas sobre el tema: “¿Es América Latina una región del mundo condenada a la humillación y a la pobreza?... ¿No será la desgracia un producto de la historia, hecha por los hombres y que por los hombres puede por lo tanto ser deshecha?" (Kovacic, 2015, p. 202) 
El concepto tercermundista también ha sido utilizado para desacreditar a los movimientos sociales y políticos que defienden y promueven la soberanía, la independencia y la autonomía de los pueblos, y a sus dirigentes se les relaciona con el atraso, el divisionismo, la falta de civilización o la oposición a la modernidad. En los sucesos de Cataluña en octubre de 2017, cuando el presidente catalán Carles Puigdemont decidió convocar a un referéndum para decidir la independencia de esa comunidad, él y otros dirigentes fueron llamados tercermundistas. El escritor Mario Vargas Llosa, a propósito de esos hechos, en una manifestación en Barcelona sentenció: "Vamos a demostrar a esos independentistas minoritarios que España es un país moderno, un país que ha hecho suya la libertad y que no va a renunciar a ella por una conjura que quiere retrocederlo a país tercermundista". La aspiración del pueblo catalán y sus dirigentes por lograr su independencia de España es desacreditada con el calificativo tercermundista. El novelista recurre a un discurso maniqueo, oponiendo independencia a modernidad, retroceso a desarrollo y libertad, y tercermundista a primermundista.

Hasta aquí puede verse que la expresión tercermundista es asociada tanto con los Gobiernos progresistas de América Latina que no se alinean al modelo económico neoliberal, como para descalificar a los dirigentes políticos que buscan libertad e independencia para sus pueblos. Estos discursos provienen de una visión dominante que siempre ha querido tener el control social de los pueblos.

\section{El tercermundismo como sumisión}

Quienes hacen estos señalamientos, vinculando tercermundismo con atraso, inferioridad, subdesarrollo, estatismo y primitivismo, no dicen lo mismo de quienes siendo latinoamericanos piensan o se comportan sumisos hacia el primer mundo, creyendo que de allá viene el progreso, el conocimiento y el desarrollo. Son actitudes e ideas que reflejan, por un lado, complejo de inferioridad hacia los países centrales y por otro, desconfianza y cuestionamiento hacia lo que hacen algunos Gobiernos democráticos de países pobres de América Latina; menosprecian sus iniciativas, logros, capacidades y esfuerzos. Estas ideas y comportamientos no son cuestionados por quienes llaman tercermundistas a los demás, sino que sucede todo lo contrario: se aprecia como natural o normal. Ser un buen latinoamericano para ellos sería asumirse menos frente al europeo, sentirse impotente ante el mundo desarrollado, pensar que las personas del primer mundo son superiores y más capaces, creer y aceptar que los latinoamericanos son atrasados, ineptos e inferiores. En el mejor de los casos estas actitudes se convierten en una invitación a la imitación. Eduardo 
Galeano dice que hay una larga tradición cultural que recompensa las virtudes del mono y del papagayo, es decir, que exalta el alto valor de la copia; donde mejor es el que mejor copia; la caricatura del norte es el destino (Gabilondo, 2004).

Los que defienden el neoliberalismo no usan el término tercermundistas para referirse a quienes expresan una actitud de minusvalía y sumisión hacia el primer mundo; esa condición condensa ausencia de dignidad, falta de autoestima y desprecio por sí mismo; pero todos esos aspectos negativos parecieran más bien convertirse en atributos. Hay ahí una especie de derrota moral y mental, expresada en una asimilación e interiorización de ser una persona vencida. Naomi Klein dice que el proyecto neoliberal tuvo éxito. Su gran triunfo ha sido convencernos de que sin ellos no hay alternativa (Precht, 2017). En todo esto es evidente el pensamiento etnocentrista, que no solo surge y se promueve desde el primer mundo, sino que también es desarrollado desde América Latina, y del cual no siempre sus portadores son conscientes. Canclini (1981), refiriéndose al etnocentrismo, señala que durante milenios el etnocentrismo -las creencias de que los valores de la propia cultura son superiores y todas las otras deben ser juzgadas de acuerdo con ellos- prevaleció en las relaciones entre los pueblos y rigió la mirada sobre uno mismo.
Hay un uso intencional de la expresión tercermundista presente en los discursos sociales y políticos, especialmente en los medios de comunicación. Si los actos represivos cometidos por el Gobierno español contra los ciudadanos de Cataluña que querían decidir su independencia se hubiera suscitado en Venezuela, entonces el Gobierno venezolano hubiera sido catalogado de tercermundista (primitivista o bárbaro), pero como se dio en España, entonces no se cuestiona, sino que se ve como un hecho que forma parte de la democracia. $\mathrm{O}$, si hubiera habido un tiroteo en Bolivia como el que hubo en Las Vegas, Estados Unidos (octubre de 2017), donde fueron asesinadas cerca de sesenta personas y más de quinientas resultaron heridas, entonces el Gobierno boliviano hubiera sido declarado culpable, porque eso sólo sucede en sociedades "atrasadas" y "salvajes", en sociedades con Gobiernos tercermundistas; pero como los hechos se suscitaron en Estados Unidos, entonces no hay por qué asombrarse o escandalizarse, porque ese es el primer mundo, y son vistos como simples disfuncionalidades sociales o desviaciones de algún individuo.

\section{Rafael Correa y los grandes medios de comunicación}

El entonces presidente de Ecuador Rafael Correa, durante sus diez años de Gobierno (2007-2017), fue uno de los presidentes latinoamericanos que más

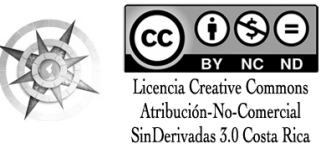


ha sido entrevistado por los medios de comunicación de América Latina, Estados Unidos y Europa. En el Internet se puede encontrar más de ochenta entrevistas que le han sido realizadas -en español, inglés y francés- por medios públicos, privados, nacionales e internacionales. Aunque la mayoría de esos diálogos los tuvo con periodistas de probada experiencia, varios de ellos han admitido que no han sido entrevistas fáciles.

Muchas de las preguntas que le han sido formuladas reflejan las percepciones y los prejuicios de los periodistas sobre los Gobiernos progresistas. Percepciones que son contrarias a las evidencias y revelan distorsión de los hechos. Las observaciones y críticas de los periodistas no solo ocultan su oposición a algunos de los Gobiernos de América Latina, sino que también expresan subestimación hacia la obra y el pensamiento de los líderes progresistas latinoamericanos en general y de Rafael Correa en particular.

A diferencia de otros políticos progresistas como José Mujica, Cristina Fernández, Luiz Inácio da Silva, Dilma Rousseff, Daniel Ortega, Nicolás Maduro y Evo Morales, que antes de ser presidentes militaron algunos años en partidos, sindicatos, movimientos sociales y grupos guerrilleros, Rafael Correa no vivió ninguna de esas experiencias, sino que pasó rápido de la academia a puestos públicos. Correa culminó sus estudios doctorales el 2001, y desde 1983 se había dedicado a la docencia universitaria. El 2005 fue nombrado ministro de Economía y Finanzas en el Gobierno de Alfredo Palacio, cargo que ocupó por cuatro meses, para luego en el 2006 fundar el movimiento Alianza PAÍS con el que ganó las elecciones a la presidencia ese mismo año.

Realizó estudios de Economía en Bélgica y los Estados Unidos; posee amplios conocimientos de la historia de América Latina y de la política internacional. Gusta de la polémica y del análisis agudo, y defiende su posición con pasión. Con el propósito de no dejar nada a la especulación suele argumentar sin límites. Es de humor fino y sarcasmo filudo, que acostumbra a usar abundantes ejemplos, no solo para sostener su punto de vista, sino para tratar de convencer a su interlocutor. Aunque una de las reglas de la entrevista periodística consiste en que el comunicador solo pregunta y el invitado solo responde, esa regla ha sido prácticamente destrozada por Correa en las entrevistas; él acostumbra a responder con otra pregunta, a repreguntar y contra preguntar; y cuando observa que su interlocutor trastabilla o titubea mostrando debilidad en sus argumentos, no duda en continuar polemizando y en cuestionar más enconadamente la posición de su anfitrión. Siempre ha dicho: "Yo vengo de la academia: en la academia el 
pecado capital es no decir la verdad, en la política el pecado capital es decirla. Lo seguiré diciendo."

Con Rafael Correa las audiencias se convirtieron en debates, porque hubo posiciones encontradas: él defendiendo un pensamiento progresista, latinoamericano y antimperialista, y los entrevistadores defendiendo posiciones neoliberales. Muchas de las cosas que ha dicho el expresidente no han sido bien recibidas por sus anfitriones; algunos de ellos a falta de argumentos para sostener sus puntos de vista han expresado impotencia e incomodidad, y no pocas veces se han quedado en silencio o han cambiado abruptamente el tema de conversación o han hecho gestos de desaprobación.

\section{Rafael Correa y el tercermundismo}

En reiteradas ocasiones sus interlocutores expresaron comentarios y afirmaciones que para él forman parte de un pensamiento que indica por un lado inferioridad, derrotismo e incapacidad, y por otro, desprecio hacia lo que se piensa y hace en América Latina; a eso él le llama tercermundismo. Indistintamente de cuál sea el tema de conversación, se observa que no siempre ellos son conscientes de los cuestionamientos que el expresidente les hace sobre esa forma de pensar. Para Correa esa visión está ligada a un pensamiento neocolonialista, eurocéntrico y etnocentrista.
En las entrevistas él usa estos términos para referirse a lo mismo: al pensamiento y a la acción que demuestran subordinación, ineptitud, invalidez y minusvalía; o a creer que en asuntos políticos los latinoamericanos no pueden hacer las cosas bien y necesitan imitar a los países desarrollados o recibir la aprobación de ellos; es expresar ese sentimiento de sentirse menos capaz o incapaz en comparación con Europa o con los Estados Unidos; incluso pensar que lo que hacen en los países centrales -no importa qué-, siempre es progreso, desarrollo, civilización y democracia, y lo que se hace en América Latina es atraso, ignorancia y dictadura.

Para entender el pensamiento del exmandatario y las objeciones hechas a sus interlocutores sobre la visión que tienen de América Latina, se analizan cuatro entrevistas. La primera fue con Ismael Cala (cubano-estadounidense) de la cadena internacional $\mathrm{CNN}$, realizada en el Palacio de Carondelet en abril de 2012; la segunda con Rory Carroll (irlandés) del periódico inglés The Guardian en Quito en julio de 2013; la tercera con Mario Saldaña (peruano) de ATV Andina en Lima en noviembre de 2013; y la cuarta con Jerry Alfaro (costarricense) de Canal 11, en San José Costa Rica en enero de 2015. Estas entrevistas se encuentran disponibles en Internet, en videos que no han sido editados. 


\section{El contexto sociopolítico de las entrevistas}

Las entrevistas se realizaron en un periodo convulso de América Latina. Desde que Hugo Chávez asumió el poder en 1999 y durante los siguientes tres lustros la región contó con Gobiernos progresistas en Paraguay, Argentina, Brasil, Uruguay, Bolivia, Ecuador, entre otros; y el acecho económico, político y mediático por parte de las oligarquías nacionales con el apoyo de Washington fue permanente; intentaron de diversas maneras desestabilizar esos Gobiernos y destituir a sus presidentes; esto hizo que se vivieran grandes tensiones y enfrentamientos entre dos modelos de sociedad: el primero, con protagonismo del Estado, orientado hacia políticas sociales, promoviendo más autonomía y soberanía nacional, y el segundo, el modelo neoliberal, donde el mercado es el eje principal de la economía, con políticas de ajuste estructural, privatización de empresas públicas y alineamiento a las directrices económicas de los organismos financieros internacionales. En ese contexto, el papel de oposición de los medios de comunicación a los Gobiernos progresistas fue protagónico. El presidente Hugo Chávez tenía un liderazgo importante en la región y contra él los grandes medios hicieron todo tipo de señalamientos. Luego de su partida física el 05 de marzo de 2015, esos señalamientos fueron dirigidos contra Rafael Correa. Ambos presidentes se caracterizaron por asumir posiciones frontales contra la prensa, defender la autodeterminación de los pueblos, cuestionar y rechazar el Área de Libre Comercio de las Américas (ALCA), condenar en foros y entrevistas el bloqueo de los Estados Unidos a Cuba, promover la unión de los países latinoamericanos para constituir un bloque y negociar en conjunto contra los países económicamente más poderosos, denunciar la política imperialista de los Estados Unidos en América Latina y el mundo, y promover el desarrollo de políticas sociales que protejan, garanticen y defiendan los derechos humanos de las personas más vulnerables. Al referirse a todo esto, Correa decía que "América Latina no vive una época de cambios, sino un verdadero cambio de época.".

\section{Entrevista para la $\mathrm{CNN}$ : superar el neocolonialismo}

El tema central giró en torno a la ausencia del presidente en la VI Cumbre de las Américas realizada en Cartagena, Colombia. Correa había anunciado que no asistiría a dicha Cumbre si Cuba no era invitada. Cuestionaba que se llamara Cumbre de las Américas y se excluyera de ella a Cuba. Pero quien excluía a Cuba no eran los miembros de la Cumbre, sino el Gobierno de los Estados Unidos, que, como país hegemónico, había vetado su 
participación. El periodista, tratando de argumentar a favor de ese veto, señala que el presidente Obama había dicho que estaba dispuesto a dialogar con las autoridades del Gobierno cubano si había una postura de flexibilidad en temas como los derechos humanos, la democracia, etc. Con ese comentario el periodista ratifica que era cierto que en las Américas había un jefe -el presidente de los Estados Unidos- que decidía quién debía participar y quién debía quedar excluido de esos eventos.

Cala recurre al tema de los derechos humanos, introduciendo la idea de que en Cuba no se respetan los derechos humanos, por lo que se justificaría el veto de ese país a la Cumbre. Usa la falacia del "argumento ad nauseam", que consiste en argüir a favor de un enunciado a través de su prolongada reiteración, por una o varias personas. Es una especie de nemotecnia utilizada por los medios de comunicación contra quienes consideren enemigo. Eso es lo que siempre se ha hecho con el tema de los derechos humanos en relación con Cuba. La falacia sirve para evitar razonamientos que no se pueden contrarrestar, repitiendo cosas ya discutidas, explicadas o refutadas. Esta falacia ayuda a reforzar afirmaciones verdaderas o falsas hasta asentarlas como parte de las creencias de un individuo o de la sociedad, convirtiéndolas en verdades incontestables.
Correa le comenta al periodista: "Maravilloso: entonces que eliminen Guantánamo, que es el mayor atropello a los derechos humanos y a la soberanía de un país". Y pregunta: "¿Quién es el presidente de los Estados Unidos para convertirse en el árbitro del bien y el mal, y decidir qué es dictadura, y qué es democracia?". Refiriéndose al bloqueo a Cuba, refuta la falacia expuesta por el periodista:

Es un atropello al derecho internacional, a los derechos humanos, a la soberanía de Cuba. Condenado decenas de veces por las Naciones Unidas -por la inmensa mayoría de las naciones- es el bloqueo criminal de la economía más grande del mundo, por más de casi medio siglo ya a Cuba; eso sí es concreto, evidente, urgente; entonces creo que el primer paso es levantar ese bloqueo criminal...es la doble moral, se pasan hablando de derechos humanos... ¿Qué peor atentado a los derechos humanos que las torturas en Guantánamo, tener una base extranjera en un país soberano como Cuba y por supuesto el criminal bloqueo? (Consuladosf, abr. 2012) El periodista trata de justificar el bloqueo contra Cuba porque en su opinión en ese país no existe democracia, por eso pregunta: "¿Para qué sirvió una de esas pocas Cumbres donde sí hubo un documento firmado que fue la Carta Interamericana de Democracia que estipula un poco hacia dónde va la democracia en el continente?"

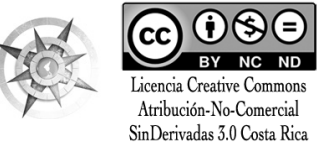


Implícitamente está diciendo que Cuba no está inserta en ese camino democrático. Correa responde desde otra perspectiva: "¿Quién dijo que la democracia liberal occidental es el único modelo de democracia?" y agrega "nadie le puede imponer a Cuba los cambios que necesiten hacer; es un país soberano y son ellos los que deciden qué es lo que quieren.”

Cala retoma la primera explicación de Correa sobre su ausencia en la Cumbre, e intenta poner en entredicho la justificación de esa ausencia, resaltando la figura de Juan Manuel Santos como organizador de la Cumbre. El objetivo es poner a rivalizar a un presidente progresista como Rafael Correa, que habría "perdido puntos" -según esa lógicacomo líder regional por ausentarse en la Cumbre, contra un presidente neoliberal como Juan Manuel Santos, que estaría "ganando puntos" por haber sido el anfitrión. En el interés de presentar al presidente de Colombia como un líder regional, el periodista dice:

El presidente Juan Manuel Santos obtuvo por la preparación obviamente de esta Cumbre y ser el anfitrión, una portada en la prestigiosa revista Time. Mucha gente lo ve no solo como el regreso de Colombia, sino también como la posibilidad de poner a Juan Manuel Santos como estratega regional, como un líder regional, algo que muchos creen que también a Rafael Correa como presidente le interesa, rebasar las fronteras de Ecuador, y que la revista Time alaba el hecho de que Colombia ha crecido económicamente y demuestra una democracia sólida en las Américas. (Consuladosf, abr. 2012)

Se apela aquí a lo que se conoce como la falacia ad verecundiam o falacia de autoridad que consiste en utilizar el "prestigio" de una persona conocida o una fuente famosa, sin aportar razones, sino invocando a alguna autoridad (en este caso la revista Time). Si bien en muchos casos es legítimo recurrir a una autoridad prestigiosa sobre el tema, no siempre eso es garantía. La revista Time es una publicación estadounidense (en inglés), que se edita semanalmente y difunde información general; el tratamiento de la política no es su especialidad, menos aún la política latinoamericana, por lo que nombrarla en estos asuntos es discutible. Por eso Correa hace la observación: "No creo que sea la revista Time y su portada la que decida si regresa un país o no al concierto internacional”, y añade, "no es la revista Time la que certifica la buena conducta, el buen comportamiento económico y la buena postura democrática." Al observar que el periodista no tiene argumentos, le pregunta: “¿Usted sabe cuántos latinoamericanos leen aquí la revista 
Time?", y remata: "Ya empecemos a pensar en función de nuestra propia realidad, de nuestras propias necesidades, a superar ese neocolonialismo. Caminemos con nuestros propios pies como decía José Gervasio Artigas”. Correa se apoya en el prócer uruguayo Artigas (1764-1850) para sustentar la idea de no actuar y pensar en función de lo que digan o juzguen elementos externos como la revista Time, ajenos a la realidad de la región. Si se está hablando de política latinoamericana entonces la opinión o el análisis de personas entendidas sobre el tema tendría importancia, pero para Correa el hecho de que su interlocutor cite a un medio como la revista Time, que no es especializada en política, es una manera de rechazarse a sí mismo, una falta de respeto, porque se asumen visiones y posturas neocoloniales, que tergiversan y/o niegan la propia realidad latinoamericana.

\section{Entrevista para The Guardian: superar el etnocentrismo}

El periodista Rory Carroll estaba interesado en el tema de la libertad de prensa. En Ecuador la Asamblea Nacional había aprobado (14 de junio de 2013) la nueva Ley de Comunicaciones. Para esa fecha Rafael Correa era conocido por su posición crítica frente a los grandes medios de comunicación, denunciándolos de haber transformado un derecho público, la información, en una mercancía. Señalaba al poder mediático como un problema para la democracia, porque se había posesionado por encima de los poderes del Estado, y no tenía ningún tipo de control social. La gran prensa era un elemento desestabilizador de la democracia, por eso decía que en "Ecuador juzgaban los titulares, no los tribunales". Fue ese poder mediático quien creó con éxito, dentro y fuera de Ecuador, la idea de que Rafael Correa era enemigo de la libertad de prensa y la libertad de expresión.

Es en ese contexto que el periodista le refiere el caso de la revista Vanguardia, la cual había dejado de circular en Ecuador. La pregunta es: "¿Está en riesgo el periodismo de investigación?", dejando entrever que la revista había sido censurada o había dejado de editarse por haber estado ejerciendo la investigación y que el Gobierno habría estado detrás de esa medida. Correa explica que la causa por la que la revista dejó de circular no fue porque se dedicaba al periodismo investigativo, sino porque hacía fraude: "Vanguardia le decía a sus auspiciadores que vendía quince mil ejemplares semanales, pero no vendía ni cinco mil". La nueva Ley de Comunicación exige a los medios publicar el tiraje de ventas, lo cual es auditado; eso permitió descubrir que Vanguardia mentía. Con la nueva ley no podían seguir cometiendo fraude (Ley Orgánica de Comunicación de Ecuador, Sección IV, Art. 90). Los auspiciadores decidieron retirar sus anuncios 
porque estaban siendo engañados. La revista quebró por mentir, no por haber hecho periodismo de investigación.

El comunicador no parece convencido con la explicación de lo sucedido e interpreta que se trata de una legislación severa y que de cierta forma el Gobierno a través de esas leyes estaría limitando el ejercicio de la libertad de prensa. La opinión de Rory Carroll tiene un tono de cuestionamiento al Estado de derecho y al propio Gobierno de Ecuador.

Al mostrar el periodista su disconformidad con la explicación, el exmandatario considera que se trata de una visión etnocentrista, y refuerza su afirmación ilustrándola con un caso sucedido en Alemania, al cual ni la prensa europea ni latinoamericana le pusieron la misma atención que ahora le ponen al caso ecuatoriano. Recuerda que en noviembre de 2010 en Alemania se cerró una radio por hacer propaganda nazi y la policía apresó a veintitrés personas. Sobre eso los medios nunca dijeron que en Alemania no había libertad de expresión, que hubo represión o abuso de poder; mientras que en Ecuador, por aprobarse una ley que busca regular los excesos de la prensa, sí se convierte en noticia. Para Correa esa doble moral con la que se aborda, estos casos se debe a que esos medios, tanto europeos como latinoamericanos, tienen una visión etnocentrista y colonialista respecto a América Latina:
Si Alemania en el 2010 cierra una radio que hace propaganda nazi y mete presa a 23 personas, es civilización; pero si en Ecuador una revista cierra, porque tiene que evidenciar los números que vende, para no estafar a sus auspiciantes, es atentado a la libertad de expresión. (Presidencia de la República del Ecuador (CSECOM, jul. 2013)

Haciendo uso de la ironía dice: "Lo que se hizo en Alemania es civilización y lo que se quiere hacer en Ecuador -que dista mucho de las medidas punitivas de Alemania- es barbarie" (Sucreranda Hugo Chávez Venezuela, abr. 2013)

El ejemplo usado por Correa evidencia que el tratamiento que los medios de comunicación -nacionales o internacionales-le dan a lo que sucede en un país del llamado tercer mundo como Ecuador, es completamente diferente al que le dan a un país del primer mundo como Alemania. Ecuador y Alemania son países con Estado de derecho, es decir, poseen leyes que responden a sus propias necesidades y contextos sociales, y lo que hacen las autoridades en casos como estos está apegado a lo que dicen sus legislaciones; sin embargo, el tratamiento y juicio que hace la prensa sobre cada caso es diferente. Mientras que en Alemania se prohíbe la propaganda nazi, en Ecuador no; en uno se apresa a quienes 
hacen ese tipo de apología, en otro no hay consecuencias por eso. Al igual que en Alemania, en Ecuador se estaba cumpliendo con la legislación establecida. La revista, al mentir a sus anunciantes, perdió auspiciadores y se vio obligada a cerrar.

En esta entrevista se juzga lo sucedido en Ecuador desde una posición de poder que de alguna manera otorga un medio. Mientras que en la primera entrevista el comunicador expresa una visión neocolonialista de los hechos, en este segundo caso, el periodista asume una perspectiva sobre Ecuador, que Correa califica de etnocentrista.

\section{Entrevista para ATV Andina: superar el tercermundismo}

Esta entrevista (noviembre de 2013) se da en un contexto en el que en América Latina, los Gobiernos progresistas venían siendo reelegidos: Lula da Silva en el 2006; ese mismo año Hugo Chávez había sido reelegido por tercera vez; Evo Morales en el 2009; Cristina Fernández en el 2011, y en el caso de Rafael Correa, acababa de ser reelegido por tercera vez en febrero de 2013. Las próximas elecciones serían en el 2017; el periodista Saldaña consulta por la posibilidad de que en Ecuador haya un cambio constitucional con el objetivo de que exista la reelección indefinida. Quiere saber si el entonces presidente apoyaba la posibilidad de la reelección.
Aunque Rafael Correa le dice "nosotros no lo hemos pensando", el periodista cuestiona esa respuesta afirmando que en América Latina los políticos suelen decir "si las bases me lo piden o si el pueblo me lo pide me aventuro a una nueva elección"; sostiene que los políticos alegan eso como una forma de ocultar sus apetitos políticos personales, para después justificar su continuidad como candidatos. Saldaña insinúa que Correa no está revelando sus verdaderas intenciones políticas de modificar la Constitución para buscar la reelección.

La observación del periodista debe entenderse en un contexto de fuertes antagonismos ideológicos y políticos entre los grandes medios en manos de las oligarquías latinoamericanas y los Gobiernos progresistas. Por primera vez en América Latina se había abierto un periodo en el que no solamente las elecciones eran ganadas por los candidatos de los partidos de izquierda, sino que los mismos eran reelegidos, democráticamente en elecciones libres, por eso los grupos oligárquicos a través del poder mediático posesionaron el tema de la reelección en la agenda diaria del debate político, arguyendo que la reelección atentaba contra la democracia, reducía las libertades y coartaba la oportunidad para que otras fuerzas políticas gobernaran. Con esos argumentos los medios desarrollaron una campaña contra la reelección de los presidentes progresis-

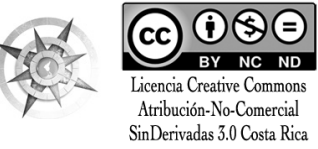


tas, pero no dijeron lo mismo sobre la reelección -de primer ministro o presidente- que se hacía en el primer mundo. Que hubiera reelección de presidentes en América Latina era reprochable, pero que hubiera lo mismo en el llamado primer mundo no. En esos años en Europa y Norteamérica había habido reelecciones: Ángela Merkel en Alemania (2005, 2009, 2013), Aníbal Cavaco en Portugal (2006 y 2011), Barack Obama en los Estados Unidos (2009, 2013), Stephen Joseph Harper Stephen en Canadá (2006, 2008, 2011), entre otros.

Correa le pregunta a su interlocutor "¿cuál sería el problema de la reelección?". Y afirma: "Si Ángela Merkel se reelige tres veces, es madurez democrática de los alemanes, pero si Chávez se reelegía era dictador vitalicio”. Cuestiona esa doble moral, porque el hecho de que haya reelección en Europa no está mal para los grandes medios, pero el hecho de que haya reelección en América Latina, sí se objeta. Dice que a América Latina no se le ve con los mismos ojos con los que se ve a Europa.

\section{Para Correa esa forma diferenciada} de ver y juzgar los acontecimientos de América Latina y Europa por parte de la prensa latinoamericana (y también la prensa europea y estadounidense) es una actitud tercermundista; asumen una posición de desprecio hacia lo que se realiza en América Latina y de elogio hacia lo que se hace en Europa o
Estados Unidos. Se trata de una minusvalía que evidencia un complejo de inferioridad. Correa piensa que no es democrático restringir las opciones de un pueblo, porque si este considera que tiene un buen Gobierno y quiere volver a reelegirlo, no se le puede impedir. Contrario a la creencia y difusión ideológica de los medios de comunicación de que la reelección presidencial atentaría contra la democracia, esta más bien -sostiene Correa- podría fortalecer la democracia, las libertades y el derecho de un pueblo a elegir a sus autoridades. $\mathrm{Al}$ argumentar el comunicador que la alternancia es buena, Correa le propone: "Dígale pues eso a Alemania, dígale pues a las monarquías europeas, ¿por qué ese tercermundismo, por qué tenemos miedo a hablar esas cosas, de enfrentarlas, de enfrentar nuestro propio pensamiento?". Dice: "En Europa no hay problema en que se reelija indefinidamente, pero aquí seríamos dictadores vitalicios." Aunque ha explicado que esa es una visión tercermundista, el periodista insiste: "Lo que pasa es que en Europa el nivel de institucionalidad y fortalecimiento democrático es diferente a América Latina”, o sea, argumenta desde su visión tercermundista. Por eso Correa le reitera: "Ahí viene el tercermundismo, porque estamos justificando que ellos son superiores y nosotros somos inferiores, entonces no podemos. Los argumentos que me estás dando se llaman tercermundismo. ¡Superemos eso!" 
Sobre este mismo tema le consultó el periodista Jerry Alfaro en el 2015, dejando entrever que los Gobiernos progresistas querían entronizarse en el poder: "Señor presidente usted ya tiene tres mandatos constitucionales, ¿considera usted que ese continuismo no significa una tendencia a la concentración de poder en el pensamiento de los países del ALBA o del suyo?" La respuesta de Correa es similar a la que le dio a Saldaña dos años antes:

Si esto pasara con Konrad Adenauer en la Alemania destruida de la posguerra, sería estabilidad. La tercera elección de Merkel sería madurez democrática de los alemanes. En América Latina es caudillismo porque le caemos mal a ciertas potencias; eso se llama democracia señores. Si quieren que no continuemos, gánennos en las urnas, pero no traten de hacer las trafasías que ciertas elites buscan para impedir la continuación de proyectos históricos que están cambiando en Nuestra América y con absoluta legitimidad democrática. (Perú info, nov. 2013)

Correa interpreta que la reelección es parte de la democracia y no es un problema para los pueblos que son los que eligen; el problema es para "ciertas potencias" y "ciertas elites" que no están de acuerdo con los Gobiernos progresistas. La reelección en América Latina, es entendida y defendida por él en función de proyectos históricos desarrollados por los gobiernos progresistas a favor de las necesidades de los pueblos. Para Correa, el pensamiento tercermundista lleva a los periodistas a justificar como válidas las reelecciones que se hacen en el primer mundo (Europa, Estados Unidos), pero a llamarlas antidemocráticas y desestabilizadoras cuando se hacen en América Latina.

\section{Entrevista para Repretel Canal 11 de Costa Rica: superar el colonialismo}

En enero de 2015 se realizó la III Cumbre de la Comunidad de Estados Latinoamericanos y Caribeños (CELAC) en Costa Rica, y el Gobierno de Ecuador recibiría el traspaso de la presidencia pro tempore, hasta esa fecha a cargo del Gobierno de Luis Guillermo Solís presidente de Costa Rica. La CELAC nació el 2010 como un mecanismo intergubernamental de diálogo y concertación política, compuesta por los treinta y tres países de América Latina y el Caribe. Surgió con el compromiso de avanzar en el proceso de integración de la región, haciendo un equilibrio entre la unidad y la diversidad política, económica, social y cultural de los 600 millones de habitantes de la región. Desde sus inicios ha buscado profundizar el diálogo entre todos los países que lo conforman, en temas como el desarrollo social, la educación, el desarme nuclear, la agricultura familiar, la cultura, las finanzas, la 
energía y el medio ambiente. También ha promovido que la región se asuma a sí misma como una comunidad de naciones, capaz de dialogar y de buscar consensos en temas de interés común. Por eso se constituyó en la voz unificada de la región en temas de consenso; y ser el único interlocutor que promueva una voz concertada de la región en la discusión de los grandes temas globales, con el objetivo de buscar una mejor inserción y proyección de la región en el ámbito internacional (CELAC, 2017).

Días previos a la Cumbre Correa, fue entrevistado por el Canal 11 Repretel. Dado el contexto en el que se desarrolló la conversación, el periodista le preguntó por la similitud entre la OEA y la CELAC. Correa, al igual que Hugo Chávez y Evo Morales, era crítico tenaz del trabajo de la OEA; esta desde su fundación y a lo largo de su historia ha jugado un papel político a favor de los intereses de Washington en la región y en contra de los Gobiernos que han buscado su independencia y autonomía. El accionar de este organismo en los últimos años a través de su secretario general Luis Almagro ha sido cuestionado.

En los pocos años de vida que tiene la CELAC han sido los Gobiernos progresistas los que más han tratado de promover los objetivos y alcances para los cuales fue creado ese organismo. Por eso, los sectores políticos conservadores y las oligarquías latinoamericanas afines a Washington siempre vieron a la CELAC como una amenaza para la sobrevivencia y propósitos de la OEA. Esto puede comprobarse en los editoriales de los medios escritos de esos años y en las declaraciones con posiciones enfrentadas por parte de los Gobiernos neoliberales y progresistas sobre el papel de la OEA. El periodista le consultó: "Hay algunos sectores dentro de la misma CELAC que propician que haya alguna similitud con la OEA, iusted está de acuerdo con eso?" La respuesta es tajante:

Yo creo que la OEA no sirve para nada. ¿Qué ha hecho pues la OEA con más de cincuenta años de bloqueo de Estados Unidos contra Cuba? ¿Qué mayor atentado de la Carta Interamericana? ¿Qué mayor atentado de los derechos humanos? Estados Unidos no ha firmado el Pacto de San José, el sustento de los derechos humanos, y tiene la sede de la Comisión Interamericana de Derechos Humanos. ¿Cómo usted puede justificar esas contradicciones? Eso sólo tiene un nombre en América Latina del siglo XXI: neocolonialismo. Es intolerable. (Corral, feb. 2015)

Para Correa hay un hecho concreto que demuestra el colonialismo existente en América Latina (expresado aquí en los medios de comunicación), y es aceptar 
que un país como los Estados Unidos hable de derechos humanos y tenga bloqueada a Cuba por más de cincuenta años; para él esa es una contradicción injustificable. Este colonialismo es más grave todavía porque se acepta que Estados Unidos exija a otras naciones en temas de derechos humanos, cuando esa nación -siendo miembro de la OEAno ha firmado el Pacto de San José de Costa Rica (suscrito en 1969 y vigente desde 1978) y que es una de las bases del Sistema Interamericano de Promoción y Protección de los Derechos Humanos. Al señalar que la OEA no sirve para nada, está diciendo que no responde a los intereses de los países latinoamericanos, pero sí a los intereses hegemónicos de los Estados Unidos.

\section{Conclusiones}

Como se señaló al principio, este trabajo buscaba hacer un estudio acerca de las connotaciones que tiene para Rafael Correa, en ese entonces presidente de Ecuador, el término tercermundista, a partir de entrevistas que tuvo con cuatro medios de comunicación, con los cuales trató temas que tienen que ver con la situación política de América Latina en general y de Ecuador en particular.

Por un lado, se observa que para Rafael Correa el tercermundismo tiene que ver con una actitud y una forma de pensar que tienen los propios latinoamericanos -hecho manifiesto en este caso a través de los propios comunicadores-, que denota sumisión, incapacidad, complejo de inferioridad y resignación.

Creen que lo que se hace en América Latina no tiene valor y por eso lo desprecian y, a su vez, imitan y elogian lo que proyectan los países centrales. Pero ese tercermundismo no solo está presente en la conducta y en el pensamiento de los latinoamericanos, sino que también lo poseen y expresan quienes viven en los llamados países centrales o desarrollados, que ven y tratan a América Latina y a los Gobiernos progresistas -como fue el Gobierno de Rafael Correa-, como si fueran naciones sin Estado de derecho y, desconfían de las gestiones de los presidentes o las presidentas, insinuando que tienen incapacidad o incompetencia, más aún si promueven y desarrollan políticas con mayor autonomía y soberanía.

Las entrevistas entre Rafael Correa y los periodistas fueron polémicas; se trataron de diálogos apasionados con posiciones políticas opuestas. Correa abordó cada uno de los temas desde una perspectiva latinoamericana, independiente y antimperialista. Por su parte, los periodistas mostraron a través de sus preguntas, repreguntas, opiniones y argumentos respecto a lo que realizan los Gobiernos progresistas visiones que Rafael Correa denomina neocolonialistas, etnocentristas, tercermundistas y colonialistas. 


\section{Referencias bibliográficas}

Canclini, N. (1981). Cultura y sociedad: una introducción. Recuperado de http://perio.unlp.edu.ar/ catedras/system/files/2.p._garcia_canclini_cultura_y_sociedad_una_introduccion.pdf

CELAC. (2017). ¿Qué es la CELAC? Recuperado de http://www.sela. org/celac/quienes-somos/quees-la-celac/

Consuladosf. (Productor). (23 de abril de 2012). Entrevista de Ismael Cala al presidente Rafael Correa en CNN. [Video]. Recuperado de https://www.youtube.com/watch? $\mathrm{v}=\operatorname{lgw} 21 \mathrm{aDAsY}$

Corral, D. (27 de febrero de 2015). Entrevista al señor presidente Rafael Correa con Canal 11 Costa Rica. [Video]. Recuperado de https:// www.youtube.com/watch?$\mathrm{v}=72 \mathrm{UH} 1 \mathrm{iNfgXQ}$

Gabilondo, I. (2004). Eduardo Galeano, ladrón de palabras [Radio]. Recuperado de http://www.podiumpodcast.com/grandes-entrevistas/temporada-2/eduardo-galeano-ladron-de-palabras/? $\mathrm{ssm}=\mathrm{fb}$

Houtart, F. (2004). Primer Mundo-Tercer Mundo. Recuperado de http:// www.cetri.be/Primer-Mundo-Tercer-Mundo?lang=fr

Kovacic, F. (2015). Galeano. Buenos Aires: Javier Vergara Editor.
Peru info. (17 de noviembre de 2013). Mario Saldaña: comentario final después de su encuentro con Rafael Correa. [Video]. Recuperado de https://www.youtube.com/watch? $v^{2}=\operatorname{muSHXrXMBx} 4$

Precht, A. (2017). Naomi Klein: "El gran triunfo del neoliberalismo ha sido convencernos de que no hay alternativa". Recuperado de http:// www.latercera.com/noticia/naomi-klein-gran-triunfo-del-neoliberalismo-ha-convencernos-no-alternativa/

Presidencia de la República del Ecuador OSECOM. (3 de julio de 2013). Entrevista del presidente Rafael Correa con el diario inglés The Guardian. [Video]. Recuperado de https://www.youtube.com/ watch? ${ }^{=}=\mathrm{vIbDqK} 8 \mathrm{WBGI}$

Registro Oficial. Órgano del Gobierno de Ecuador. (2013). Ley Orgánica de Comunicación. Recuperado de: http://www.arcotel.gob.ec/ wp-content/uploads/downloads/2013/07/ley_organica_ comunicacion.pdf

RPP Noticias. (08 de octubre de 2017). Vargas Llosa: "La conjura independentista quiere retroceder Cataluña al tercermundismo". Recuperado de http://rpp.pe/ mundo/espana/video-vargas-llosa-afirmo-que-muchos-catalanes-no-se-sienten-independentistas-noticia-1081300 
Sauvy, A. (1952). Trois mondes, une planète. Recuperado de http:// www.homme-moderne.org/societe/ demo/sauvy/3mondes.html
Sierra, Y. (2012). Los impactos de la globalización neoliberal en América Latina. Recuperado de http://rcci.net/ globalizacion/2012/fg1357.htm 